\title{
Near-Edge X-Ray Absorption Fine Structure of Ultrananocrystalline Diamond/Hydrogenated Amorphous Carbon Films Prepared by Pulsed Laser Deposition
}

\author{
Shinya Ohmagari, ${ }^{1}$ Tsuyoshi Yoshitake, ${ }^{1}$ Akira Nagano, ${ }^{1}$ Sausan AL-Riyami, ${ }^{1}$ Ryota Ohtani, ${ }^{2}$ \\ Hiroyuki Setoyama, ${ }^{2}$ Eiichi Kobayashi, ${ }^{2}$ and Kunihito Nagayama $^{3}$ \\ ${ }^{1}$ Department of Applied Science for Electronics and Materials, Kyushu University, 6-1 Kasuga, Fukuoka 816-8580, Japan \\ ${ }^{2}$ Kyushu Synchrotron Light Research Center, 8-7 Yayoigaoka, Tosu, Saga 841-0005, Japan \\ ${ }^{3}$ Department of Aeronautics and Astronautics, Kyushu University, 744 Motooka, Nishi-ku, Fukuoka 819-0395, Japan
}

Correspondence should be addressed to Tsuyoshi Yoshitake, tsuyoshi_yoshitake@kyudai.jp

Received 17 January 2009; Revised 17 January 2009; Accepted 19 February 2009

Recommended by Rakesh Joshi

The atomic bonding configuration of ultrananocrystalline diamond (UNCD)/hydrogenated amorphous carbon (a-C:H) films prepared by pulsed laser ablation of graphite in a hydrogen atmosphere was examined by near-edge X-ray absorption fine structure spectroscopy. The measured spectra were decomposed with simple component spectra, and they were analyzed in detail. As compared to the a-C:H films deposited at room substrate-temperature, the UNCD/a-C:H and nonhydrogenated amorphous carbon (a-C) films deposited at a substrate-temperature of $550^{\circ} \mathrm{C}$ exhibited enhanced $\pi^{*}$ and $\sigma^{*} \mathrm{C} \equiv \mathrm{C}$ peaks. At the elevated substrate-temperature, the $\pi^{*}$ and $\sigma^{*} \mathrm{C} \equiv \mathrm{C}$ bonds formation is enhanced while the $\sigma^{*} \mathrm{C}-\mathrm{H}$ and $\sigma^{*} \mathrm{C}-\mathrm{C}$ bonds formation is suppressed. The UNCD/a-C:H film showed a larger $\sigma^{*} \mathrm{C}-\mathrm{C}$ peak than the a-C film deposited at the same elevated substratetemperature in vacuum. We believe that the intense $\sigma^{*} \mathrm{C}-\mathrm{C}$ peak is evidently responsible for UNCD crystallites existence in the film.

Copyright (C) 2009 Shinya Ohmagari et al. This is an open access article distributed under the Creative Commons Attribution License, which permits unrestricted use, distribution, and reproduction in any medium, provided the original work is properly cited.

\section{Introduction}

Ultrananocrystalline diamond (UNCD) films comprising diamond crystallites with diameters less than $10 \mathrm{~nm}$ and an amorphous carbon matrix $[1,2]$ have attracted considerable attention from the physical and technological viewpoints because of the following features: (i) some properties resembling those of diamond and $\mathrm{sp}^{3}$-rich amorphous carbon, so-called diamond-like carbon (DLC); (ii) smooth surface [3], which is contrastive to that of polycrystalline diamond; (iii) higher temperature stability as compared to that of DLC; (iv) unique optical and electrical properties owing to a large number of grain boundaries in the film [4]. Here, the grain boundaries exactly mean the interfaces between UNCDs and between an amorphous carbon matrix and UNCDs. It has been theoretically predicted that a large number of grain boundaries generate additional energy states between the bottom of the conduction band and the top of the valence band of diamond [5]. Experimentally, a large absorption coefficient caused by the direct optical bandgap with a value of $2.2 \mathrm{eV}$ that might be due to grain boundaries has been reported [6]. As for the electrical properties, the $n$-type conduction of nitrogen-doped UNCD films is realized by the grain boundary conductions [7]. The effects of the grain boundaries on the film properties are hot topics specific to the UNCD films. The local atomic structure in the UNCD films significantly influences their physical properties. However, thus far, there have been a few researches on the local atomic structure $[8,9]$.

Raman spectroscopy has ever been widely utilized for the characterization of carbon-based materials $[10,11]$. However, this technique has the following shortcomings for the structural measurement of mixed $\mathrm{sp}^{2}-$ and $\mathrm{sp}^{3}$ - bonded carbon materials. (i) There is the large difference in the 
Raman cross-section between $\mathrm{sp}^{2}$ and $\mathrm{sp}^{3}$ bonds. The Raman cross-section for graphitic features can be up to 50 times compared to that of diamond [12]. This results in the extremely large sensitivity to the $\mathrm{sp}^{2}$ bonds as compared to the $\mathrm{sp}^{3}$ bonds [13]. (ii) Long range ordering factors in the materials indirectly contribute to the spectrum in Raman spectroscopy. Since the wavelength of an incident probe beam is on the order of micrometers, the sensitivity is strongly dependent on the wavelength of the incident beam and the crystallite size in materials. The detectable crystallite size has a critical value that depends on the wavelength of the incident beam. An ultraviolet incident beam is required for the detection of nanocrystalline diamond. From these shortcomings, for amorphous or nanocrystalline carbon wherein $\mathrm{sp}^{2}$ and $\mathrm{sp}^{3}$ bonds coexist, the qualification of the $\mathrm{sp}^{2}$ and $\mathrm{sp}^{3}$ bond fractions in their mixed materials is difficult to be reliably performed.

On the other hand, Near-edge X-ray absorption fine structure (NEXAFS) spectroscopy can overcome these problems. This spectroscopy probes the final-state wave function near the excited atom wherein transitions from the $\mathrm{C} 1 \mathrm{~s}$ core level to the unoccupied states area are caused by X-ray photon absorption. The dominant interaction terms could be approximated to those between the localized bonds. Thus the NEXAFS spectrum can roughly be decomposed with the simple component spectra $[14,15]$.

NEXAFS spectroscopy has been successfully utilized for investigating the local bonding configurations within amorphous and nanocrystalline carbon. For amorphous carbon films, the spectrum has been decomposed into the components spectra originating from $\pi^{*}$ and $\sigma^{*}$ bonds, and the bonding configuration structure has been studied in detail $[16,17]$. The $\mathrm{sp}^{2}$ fraction estimation method that has been established in electron energy loss spectroscopy (EELS) is applicable to the NEXAFS measurement $[18,19]$. For hydrogenated amorphous carbon $[15,20]$ and nitrogendoped amorphous carbon films [21, 22], the bonding configurations of hydrogen and nitrogen atoms with carbon atoms have been investigated. For UNCD films, on the other hand, there have been a few researches thus far $[9,23]$.

As above-mentioned, the UNCD films have the complicated structure including the grain boundaries, which must have a significant role on the unique physical properties of the UNCD films. In this paper, we discuss on the atomic bonding configuration of UNCD/hydrogenated amorphous carbon (a-C:H) composite films by analyzing the NEXAFS spectra. Here we call our films "UNCD/a-C:H" films since UNCD crystallites are exactly surrounded by an a-C:H matrix. The peak decomposition of the measured spectrum revealed the specific bonding configuration to the UNCD/aC:H films.

\section{Experimental}

UNCD/a-C:H films were deposited on $\mathrm{Si}$ substrates at a substrate-temperature $\left(T_{\mathrm{s}}\right)$ of $550^{\circ} \mathrm{C}$ and an ambient hydrogen pressure $\left(P_{\mathrm{H} 2}\right)$ of $53.3 \mathrm{~Pa}$ by pulsed laser deposition (PLD) using a graphite target. The detailed conditions have been indicated in our previous paper [6]. For comparison,

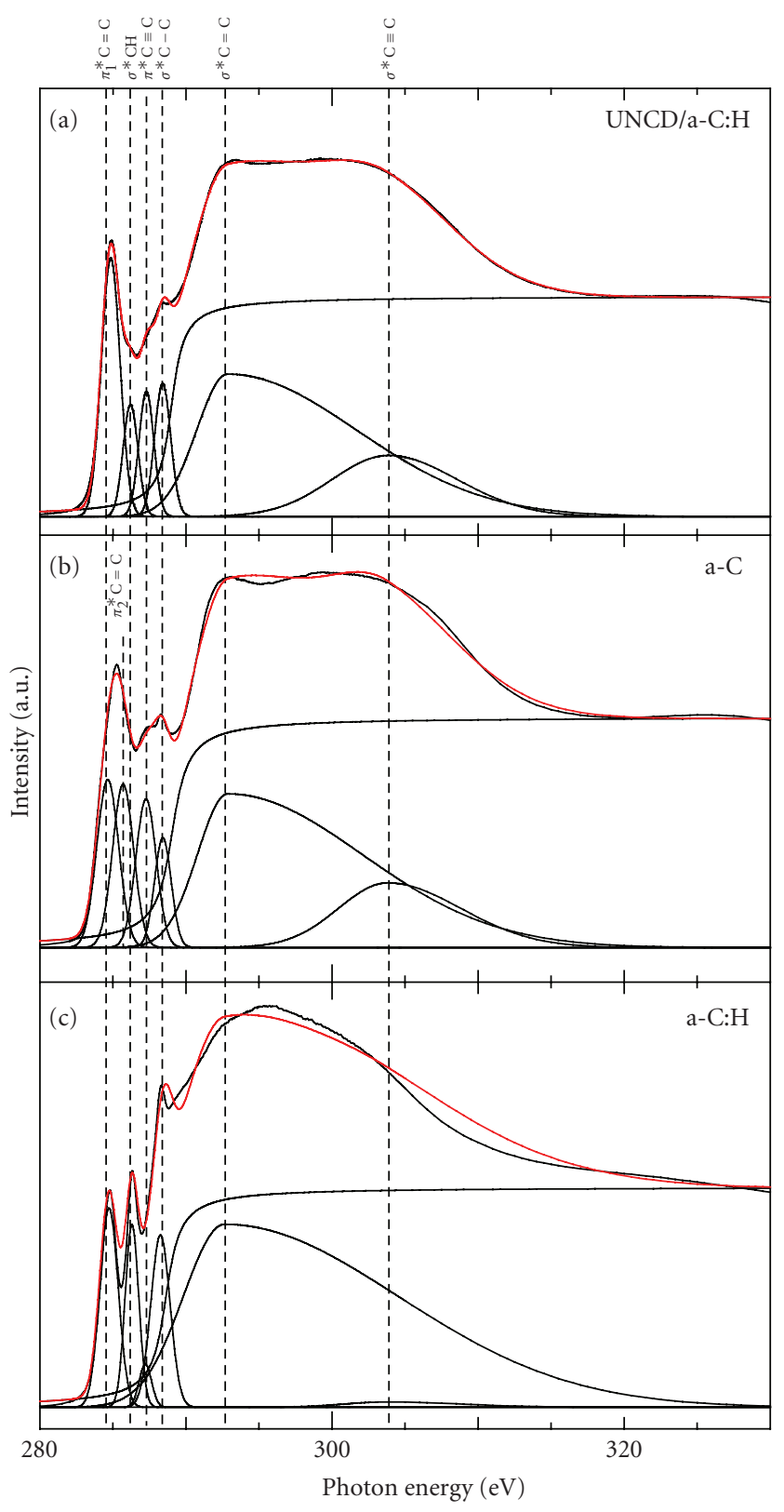

FiguRE 1: NEXAFS spectra, which are decomposed with an errorfunction step and Gaussians, of (a) UNCD/a-C:H film deposited at $T_{\mathrm{s}}=550^{\circ} \mathrm{C}$ and $P_{\mathrm{H} 2}=53.3 \mathrm{~Pa}$, (b) a-C film deposited at $T_{\mathrm{s}}=$ $550^{\circ} \mathrm{C}$ in vacuum, and (c) a-C:H film deposited at $T_{\mathrm{s}}=\mathrm{RT}$ and $P_{\mathrm{H} 2}=53.3 \mathrm{~Pa}$.

hydrogenated amorphous carbon (a-C:H) and nonhydrogenated amorphous carbon (a-C) films were prepared at $T_{\mathrm{s}}=$ room temperature $(\mathrm{RT})$ in $53.3 \mathrm{~Pa}$ hydrogen and $T_{s}=550^{\circ} \mathrm{C}$ in vacuum, respectively. The UNCDs formation was confirmed by transmission electron microscopy (TEM). NEXAFS was performed on the UNCD/a-C:H, a-C:H, and a$\mathrm{C}$ films with the same thickness of $100 \mathrm{~nm}$. NEXAFS spectra were taken in a total electron yield mode by measuring the current from the sample to ground using synchrotron radiation at the beam line 12 of SAGA Light Source. Highly 
TABLE 1: Comparison of the peak positions and FWHMs of the decomposed component spectra of the UNCD/a-C:H films deposited at $T_{\mathrm{s}}=550^{\circ} \mathrm{C}$ and $P_{\mathrm{H} 2}=53.3 \mathrm{~Pa}$, a-C films deposited at $T_{\mathrm{s}}=550^{\circ} \mathrm{C}$ in vacuum, a-C:H films deposited at $T_{\mathrm{s}}=\mathrm{RT}$ and $P_{\mathrm{H} 2}=53.3 \mathrm{~Pa}$ in this study, and carbon films in previous reports.

\begin{tabular}{|c|c|c|c|c|c|c|c|}
\hline & $\pi_{1}{ }^{*} \mathrm{C}=\mathrm{C}(\mathrm{eV})$ & $\pi_{2}{ }^{*} \mathrm{C}=\mathrm{C}(\mathrm{eV})$ & $\sigma^{*} \mathrm{C}-\mathrm{H}(\mathrm{eV})$ & $\pi^{*} \mathrm{C} \equiv \mathrm{C}(\mathrm{eV})$ & $\sigma^{*} \mathrm{C}-\mathrm{C}(\mathrm{eV})$ & $\sigma^{*} \mathrm{C}=\mathrm{C}(\mathrm{eV})$ & $\sigma^{*} \mathrm{C} \equiv \mathrm{C}(\mathrm{eV})$ \\
\hline \multicolumn{8}{|c|}{ UNCD/a-C:H } \\
\hline position & 284.87 & & 286.22 & 287.27 & 288.42 & 292.87 & 303.81 \\
\hline FWHM & 1.48 & & 1.50 & 1.30 & 1.30 & & \\
\hline \multicolumn{8}{|l|}{$\mathrm{a}-\mathrm{C}$} \\
\hline position & 284.65 & 285.70 & & 287.27 & 288.42 & 292.87 & 303.81 \\
\hline FWHM & 1.76 & 1.70 & & 1.64 & 1.35 & & \\
\hline \multicolumn{8}{|l|}{$\mathrm{a}-\mathrm{C}: \mathrm{H}$} \\
\hline position & 284.73 & & 286.30 & 287.22 & 288.25 & 292.65 & 303.81 \\
\hline FWHM & 1.48 & & 1.10 & 1.00 & 1.55 & & \\
\hline \multicolumn{8}{|c|}{$<$ Previous reports $>$} \\
\hline \multirow{3}{*}{ position } & $285^{(\mathrm{a})}[26]$ & $286^{(\mathrm{b})}[15]$ & $287.5^{(\mathrm{a})}[26]$ & & $289.3^{(\mathrm{c})}[24]$ & $292.7^{(\mathrm{d})}[22]$ & \\
\hline & $284^{(\mathrm{b})}[27]$ & & $287^{(\mathrm{b})}[27]$ & & & & \\
\hline & $284.6^{(\mathrm{b})}[15]$ & & & & & & \\
\hline
\end{tabular}

oriented pyrolytic graphite (HOPG) was used as a sample reference for the energy calibration.

\section{Results and Discussion}

The NEXAFS spectra of the UNCD/a-C:H film deposited at $T_{\mathrm{s}}=550^{\circ} \mathrm{C}$ and $P_{\mathrm{H} 2}=53.3 \mathrm{~Pa}$, a-C film deposited at $T_{\mathrm{s}}=550^{\circ} \mathrm{C}$ in vacuum, and a-C: $\mathrm{H}$ film deposited at $T_{\mathrm{s}}=$ RT and $P_{\mathrm{H} 2}=53.3 \mathrm{~Pa}$ are shown in Figures $1(\mathrm{a}), 1(\mathrm{~b})$, and $1(\mathrm{c})$, respectively. These spectra were normalized in intensity at $330 \mathrm{eV}$. The spectra consist of two major peaks. One peak centered at $285 \mathrm{eV}$ is due to the $\pi^{*}$ bonding structure. The other peak positioned between 290 and $295 \mathrm{eV}$ originates from the $\sigma^{*}$ bonding structure. In the photon energy range between 285 and $290 \mathrm{eV}$, there is the obvious difference in the spectrum between the films. This implies that several peaks are superpositioned in this range.

The $\mathrm{sp}^{2}$ fraction was estimated using the following equation:

$$
f_{\mathrm{sp} 2}=\frac{I_{\mathrm{sam}}^{\pi *} I_{\mathrm{ref}}(\Delta E)}{I_{\mathrm{ref}}^{\pi *} I_{\mathrm{sam}}(\Delta E)}
$$

where $I_{\text {sam }}^{\pi *}$ and $I_{\text {ref }}^{\pi *}$ are the area of the $\pi^{*}$ peak of the samples and reference HOPG, respectively, and $I_{\text {sam }}(\Delta E)$ and $I_{\text {ref }}(\Delta E)$ are the areas calculated under the remainder of each spectrum from $288.6 \mathrm{eV}$ to $315 \mathrm{eV}$ [24]. The $\mathrm{sp}^{2}$ fractions were estimated to be $58 \%, 67 \%$, and $40 \%$ for the UNCD/a$\mathrm{C}: \mathrm{H}, \mathrm{a}-\mathrm{C}$, and a-C:H films, respectively. The a-C:H film deposited at $T_{\mathrm{s}}=\mathrm{RT}$ shows the less $\mathrm{sp}^{2}$ fraction as compared to the others deposited at $T_{\mathrm{s}}=550^{\circ} \mathrm{C}$. The $\mathrm{sp}^{2}$ fraction of the UNCD/a-C:H film is smaller than that of a-C film, which might be mainly because of the existence of UNCD crystallites in the UNCD/a-C:H film.

In order to analyze the atomic bonding configuration in detail, the NEXAFS spectra were decomposed into component peaks. The decomposition was carried out based on the following assumptions. (a) The peak profile is predominantly responsible for the wave function; it cannot be dramatically changed between the similar kind of materials. (b) The peak profiles of the fitting component spectra were supposed to be approximately uniform between the samples. (c) The peak position was also almostly fixed because the bond length does not dramatically differ from those of similar materials.

The decomposed spectra of the UNCD/a-C:H, a-C, and $\mathrm{a}-\mathrm{C}: \mathrm{H}$ films are shown in Figures 1(a), 1(b), and 1(c), respectively. The integral spectrum resulting from the decomposed component spectra is shown in red solid line. The jump of the C K-edge at the ionization potential was fitted with an error-function step, and the subtracted spectra are decomposed into Gaussian peaks $[14,25]$. The spectra were decomposed with the component spectra due to $\pi^{*} \mathrm{C}=\mathrm{C}, \sigma^{*} \mathrm{C}-\mathrm{H}, \pi^{*} \mathrm{C} \equiv \mathrm{C}^{*}, \sigma^{*} \mathrm{C}-\mathrm{C}, \sigma^{*} \mathrm{C}=\mathrm{C}$, and $\sigma^{*} \mathrm{C} \equiv \mathrm{C}$. Here, the a-C film showed the obviously wide $\pi^{*} \mathrm{C}=\mathrm{C}$ peak as compared to the other films. The $\pi^{*} \mathrm{C}=\mathrm{C}$ peak of the a-C film was decomposed into two. This implies that the bonds with different bond lengths coexist in the a-C film. Table 1 shows the peak position and full width at half maximum (FWHM) of the decomposed component spectrum.

There are two obvious differences between the UNCD/a$\mathrm{C}: \mathrm{H}$ and a-C films. One is that the $\sigma^{*} \mathrm{C} \equiv \mathrm{C}$ weakens and the $\sigma^{*} \mathrm{C}-\mathrm{H}$ peak appears for the UNCD/a-C:H film. The $\sigma^{*} \mathrm{C} \equiv \mathrm{C}$ bonds are partially replaced with the $\sigma^{*} \mathrm{C}-\mathrm{H}$ bonds by hydrogenation. The other is that the UNCD/a-C:H shows the greater $\sigma^{*} \mathrm{C}-\mathrm{C}$ peak than that of the a-C film. In the spectrum of the UNCD/a-C:H film, the $\sigma^{*} \mathrm{C}-\mathrm{C}$ peak is relatively intense as compared to the $\sigma^{*} \mathrm{C}-\mathrm{H}$ and $\pi^{*} \mathrm{C} \equiv \mathrm{C}$ peaks. This is different from the other spectra. And the UNCD crystallites were confirmed by TEM only in the $\mathrm{UNCD} / \mathrm{a}-\mathrm{C}: \mathrm{H}$ film. We believe that the relatively intense $\sigma^{*} \mathrm{C}-\mathrm{C}$ peak is responsible for the existence of UNCDs.

In comparison with the a-C:H film, there are the following differences. (i) The UNCD/a-C:H film including the a-C film deposited at $T_{\mathrm{s}}=550^{\circ} \mathrm{C}$ showed stronger $\pi^{*}$ 
and $\sigma^{*} \mathrm{C} \equiv \mathrm{C}$ peaks than the a-C:H film deposited at $T_{\mathrm{s}}=\mathrm{RT}$. The $\mathrm{C} \equiv \mathrm{C}$ bonds formation is enhanced at the elevated $T_{s}$. (ii) The a-C:H film showed intense $\sigma^{*} \mathrm{C}-\mathrm{H}$ and $\sigma^{*} \mathrm{C}-\mathrm{C}$ peaks instead of the $\pi^{*}$ and $\sigma^{*} \mathrm{C} \equiv \mathrm{C}$ peaks being weakened. Since the a-C:H film was deposited at $T_{\mathrm{s}}=\mathrm{RT}$, the intense $\sigma^{*} \mathrm{C}-$ $\mathrm{H}$ peak might result from a large amount of hydrogen in the film as compared to the UNCD/a-C:H film. At $T_{\mathrm{s}}=\mathrm{RT}$, the $\sigma^{*} \mathrm{C}-\mathrm{C}$ bonds, instead of the $\mathrm{C} \equiv \mathrm{C}$ bonds, were preferentially formed in the amorphous film.

\section{Conclusion}

The chemical bonding structure of the ultrananocrystalline diamond/hydrogenated amorphous carbon composite films prepared by pulsed laser deposition was investigated by nearedge X-ray absorption fine structure spectroscopy. The ultrananocrystalline diamond/hydrogenated amorphous carbon and amorphous carbon films deposited at the substratetemperature of $550^{\circ} \mathrm{C}$ in $53.3 \mathrm{~Pa}$ hydrogen atmosphere and vacuum showed larger $\pi^{*}$ and $\sigma^{*} \mathrm{C} \equiv \mathrm{C}$ peaks than that of hydrogenated amorphous carbon film deposited at room substrate-temperature in $53.3 \mathrm{~Pa}$ hydrogen atmosphere. The ultrananocrystalline diamond/hydrogenated amorphous carbon composite films showed a greater $\sigma^{*} \mathrm{C}-\mathrm{C}$ peak as compared to the amorphous carbon film. This is evidently responsible for the existance of ultrananocrystalline diamond crystallites in the film.

\section{References}

[1] T. Yoshitake, T. Hara, T. Fukugawa, et al., "Low-temperature growth of nanocrystalline diamond by reactive pulsed laser deposition under a hydrogen atmosphere," Japanese Journal of Applied Physics, Part 2, vol. 43, no. 2B, pp. L240-L242, 2004.

[2] T. Hara, T. Yoshitake, T. Fukugawa, et al., "Ultrananocrystalline diamond prepared by pulsed laser deposition," Diamond and Related Materials, vol. 15, no. 4-8, pp. 649-653, 2006.

[3] T. Hara, T. Yoshitake, T. Fukugawa, et al., "Nanocrystalline diamond film prepared by pulsed laser deposition in a hydrogen atmosphere," Diamond and Related Materials, vol. 13, no. 4-8, pp. 679-683, 2004.

[4] F. Cleri, P. Keblinski, L. Colombo, D. Wolf, and S. R. Phillpot, "On the electrical activity of $s p^{2}$-bonded grain boundaries in nanocrystalline diamond," Europhysics Letters, vol. 46, no. 5, pp. 671-677, 1999.

[5] P. Zapol, M. Sternberg, L. A. Curtis, T. Frauenheim, and D. M. Gruen, "Tight-binding molecular-dynamics simulation of impurities in ultrananocrystalline diamond grain boundaries," Physical Review B, vol. 65, no. 4, Article ID 045403, 11 pages, 2001.

[6] T. Yoshitake, A. Nagano, M. Itakura, N. Kuwano, T. Hara, and K. Nagayama, "Spectral absorption properties of ultrananocrystalline diamond/amorphous carbon composite thin films prepared by pulsed laser deposition," Japanese Journal of Applied Physics, Part 2, vol. 46, no. 36-40, pp. L936-L938, 2007.

[7] S. Bhattacharyya, O. Auciello, J. Birrell, et al., "Synthesis and characterization of highly-conducting nitrogen-doped ultrananocrystalline diamond films," Applied Physics Letters, vol. 79, no. 10, pp. 1441-1443, 2001.
[8] Y. C. Chen, X. Y. Zhong, A. R. Konicek, et al., "Synthesis and characterization of smooth ultrananocrystalline diamond films via low pressure bias-enhanced nucleation and growth," Applied Physics Letters, vol. 92, no. 13, Article ID 133113, 3 pages, 2008.

[9] C. Poppv, W. Kulisch, S. Boycheva, K. Yamamoto, G. Ceccone, and Y. Koga, "Structural investigation of nanocrystalline diamond/amorphous carbon composite films," Diamond and Related Materials, vol. 13, no. 11-12, pp. 2071-2075, 2004.

[10] Y. Hirose and Y. Terasawa, "Synthesis of diamond thin films by thermal CVD using organic compounds," Japanese Journal of Applied Physics, Part 2, vol. 25, no. 6, pp. L519-L521, 1986.

[11] M. S. Dresselhaus, M. A. Pimenta, P. C. Eklund, and G. Dresselhaus, "Raman scattering in fullerenes and related carbon-based materials," in Raman Scattering in Materials Science, W. H. Weber and R. Merlin, Eds., pp. 314-368, Springer, Berlin, Germany, 2000.

[12] D. S. Knight and W. B. White, "Characterization of diamond films by Raman spectroscopy," Journal of Materials Research, vol. 4, no. 2, pp. 385-393, 1989.

[13] F. L. Coffman, R. Cao, P. A. Pianetta, S. Kapoor, M. Kelly, and L. J. Terminello, "Near-edge X-Ray absorption of carbon materials for determining bond hybridization in mixed sp2/sp3 bonded materials," Applied Physics Letters, vol. 69, no. 4, pp. 568-570, 1996.

[14] J. Stöhr, NEXAFS Spectroscopy, Springer, New York, NY, USA, 1992.

[15] J. Díaz, S. Anders, X. Zhou, E. J. Moler, S. A. Kellar, and Z. Hussain, "Analysis of the $\pi^{*}$ and $\sigma^{*}$ bands of the X-Ray absorption spectrum of amorphous carbon," Physical Review B, vol. 64, no. 12, Article ID 125204, 19 pages, 2001.

[16] J. Díaz, O. R. Monteiro, and Z. Hussain, "Structure of amorphous carbon from near-edge and extended X-Ray absorption spectroscopy," Physical Review B, vol. 76, no. 9, Article ID 094201, 12 pages, 2007.

[17] C. Lenardi, P. Piseri, V. Briois, C. E. Bottani, A. Li Bassi, and P. Milani, "Near-edge X-Ray absorption fine structure and Raman characterization of amorphous and nanostructured carbon films," Journal of Applied Physics, vol. 85, no. 10, pp. 7159-7167, 1999.

[18] K. Kanda, T. Kitagawa, Y. Shimizugawa, et al., "Characterization of hard diamond-like carbon films formed by $\mathrm{Ar}$ gas cluster ion beam-assisted fullerene deposition," Japanese Journal of Applied Physics, Part 1, vol. 41, no. 6B, pp. 42954298, 2002.

[19] J. Birrell, J. E. Gerbi, O. Auciello, J. M. Gibson, D. M. Gruen, and J. A. Carlisle, "Bonding structure in nitrogen doped ultrananocrystalline diamond," Journal of Applied Physics, vol. 93, no. 9, pp. 5606-5612, 2003.

[20] C. Lenardi, M. A. Baker, V. Briois, L. Nobili, P. Piseri, and W. Gissler, "Properties of amorphous a-CH(:N) films synthesized by direct ion beam deposition and plasma-assisted chemical vapour deposition," Diamond and Related Materials, vol. 8, no. 2-5, pp. 595-600, 1999.

[21] S. S. Roy, R. McCann, P. Papakonstantinou, et al., "Near edge X-Ray absorption fine structure study of aligned $\pi$ bonded carbon structures in nitrogenated ta-C films," Journal of Applied Physics, vol. 99, no. 4, Article ID 043511, 5 pages, 2006.

[22] S. Bhattacharyya, M. Lübbe, and F. Richter, "Near edge X-Ray absorption fine structure of thermally annealed amorphous nitrogenated carbon films," Journal of Applied Physics, vol. 88, no. 9, pp. 5043-5049, 2000. 
[23] A. V. Sumant, D. S. Grierson, J. E. Gerbi, J. A. Carlisle, O. Auciello, and R. W. Carpick, "Surface chemistry and bonding configuration of ultrananocrystalline diamond surfaces and their effects on nanotribological properties," Physical Review B, vol. 76, no. 23, Article ID 235429, 11 pages, 2007.

[24] A. V. Sumant, P. U. P. A. Gilbert, D. S. Grierson, et al., "Surface composition, bonding, and morphology in the nucleation and growth of ultra-thin, high quality nanocrystalline diamond films," Diamond and Related Materials, vol. 16, no. 4-7, pp. 718-724, 2007.

[25] D. A. Outka and J. Stöhr, "Curve fitting analysis of nearedge core excitation spectra of free, adsorbed, and polymeric molecules," The Journal of Chemical Physics, vol. 88, no. 6, pp. 3539-3554, 1988.

[26] A. Hoffman, A. Heiman, H. P. Strunk, and S. H. Christiansen, "Microstructure and phase composition evolution of nanocrystalline carbon films: dependence on deposition temperature," Journal of Applied Physics, vol. 91, no. 5, pp. 3336-3344, 2002.

[27] T.-Y. Kim, C. S. Lee, Y. J. Lee, K.-R. Lee, K.-H. Chae, and K. H. Oh, "Reduction of the residual compressive stress of tetrahedral amorphous carbon film by Ar background gas during the filtered vacuum arc process," Journal of Applied Physics, vol. 101, no. 2, Article ID 023504, 5 pages, 2007. 

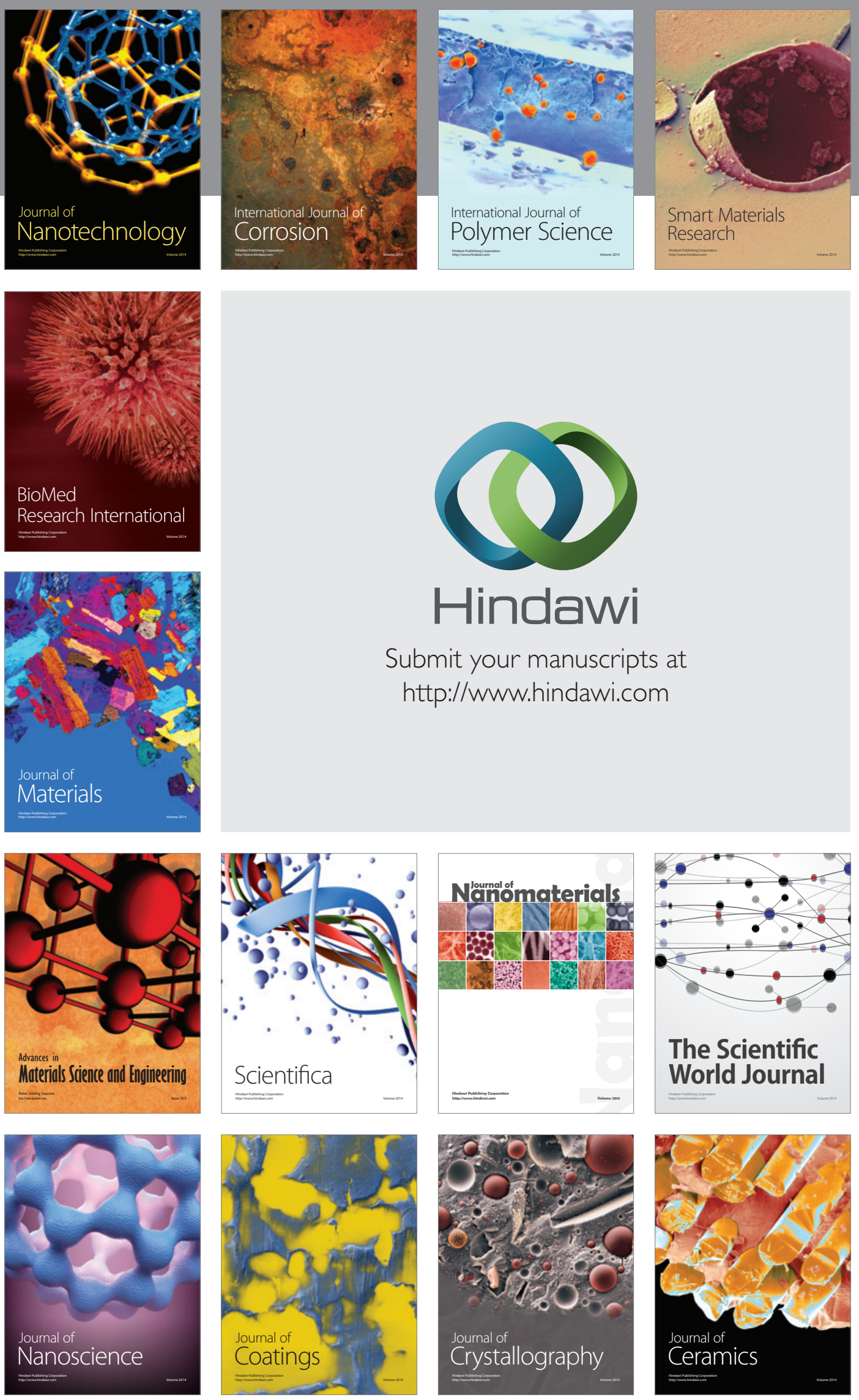

The Scientific World Journal

Submit your manuscripts at

http://www.hindawi.com

\section{World Journal}

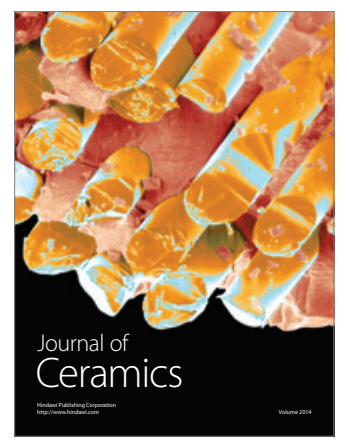

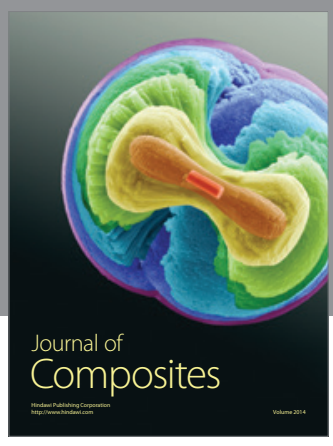
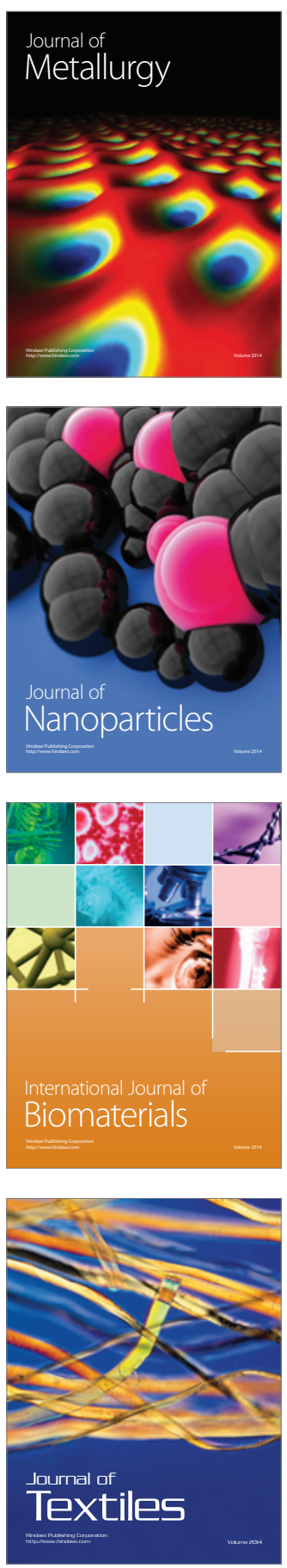